\title{
Reimpermeabilización, casos prácticos
}

\author{
Vara Mora, Tatiana ${ }^{1}$, Dolores Cabrera, $\mathbf{M}^{\mathrm{a}}$ Dolores $^{1}$, Solera Martínez, Rosario ${ }^{2}$, Mateo Sanz, Beatriz
}

1 EPEL BALTEN; t.vara@balten.es

2 Laboratorio Central de Estructuras y Materiales, CEDEX; Rosario.Solera@cedex.es

Resumen: Cuando en los años 80 se impermeabilizó con geosintéticos, estos materiales resultaron una técnica novedosa y única para poder superar la permeabilidad de los terrenos volcánicos de Tenerife. Ante la necesidad de realizar trabajos de seguimiento del comportamiento de los distintos materiales se contactó con el Centro de Estructuras y Materiales de Obras Públicas (CEDEX) dependiente del Ministerio de Fomento ya que, su Laboratorio Central de Estructuras y Materiales, en el sector de Materiales, disponía de los medios especializados para la realización de los mismos. Gracias a los resultados obtenidos en los 31 años de convenios se ha podido planificar y programar las distintas actuaciones en las pantallas de impermeabilización de los embalses de Canarias. Los condicionantes que nos encontramos y que tenemos que tener en cuenta a la hora de reimpermeabilizar son: Comportamiento del material, Material instalado anteriormente, Tipología de la balsa y Ciclo del agua. De esta forma hemos conseguido: A) Rentabilización de la obra Pública, B) Planificación y programación de las actuaciones en las pantallas y C) Incremento de la vida útil de las pantallas, siempre en la franja de seguridad que nos ampara los ensayos realizados por el CEDEX, "no es gastar más ni menos, es gastar bien"

Palabras clave: reimpermeabilización; balsa; geosintéticos. 